\title{
Identification of high protein kinase CK2 $\alpha$ in HPV(+) oropharyngeal squamous cell carcinoma and correlation with clinical outcomes
}

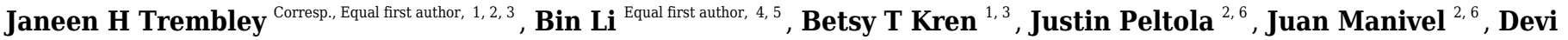 \\ Meyyappan ${ }^{7}$, Amy Gravely ${ }^{1}$, Mark Klein ${ }^{3,7,8}$, Khalil Ahmed ${ }^{1,2,3,5}$, Emiro Caicedo-Granados ${ }^{3,4,5}$ \\ ${ }^{1}$ Research Service, Minneapolis VA Health Care System, Minneapolis, MN, United States \\ 2 Department of Laboratory Medicine and Pathology, University of Minnesota - Twin Cities Campus, Minneapolis, MN, United States \\ 3 Masonic Cancer Center, University of Minnesota - Twin Cities Campus, Minneapolis, MN, United States \\ 4 Otolaryngology Section, Minneapolis VA Health Care System, Minneapolis, MN, United States \\ 5 Department of Otolaryngology, University of Minnesota - Twin Cities Campus, Minneapolis, MN, United States \\ 6 Laboratory Medicine and Pathology Service, Minneapolis VA Health Care System, Minneapolis, MN, United States \\ 7 Hematology and Oncology Section, Minneapolis VA Health Care System, Minneapolis, MN, United States \\ 8 Department of Medicine, University of Minnesota - Twin Cities Campus, Minneapolis, MN, United States \\ Corresponding Author: Janeen H Trembley \\ Email address: trem0005@umn.edu
}

Background. Oropharyngeal squamous cell carcinoma (OPSCC) incidence is rising worldwide, especially human papillomavirus (HPV)-associated disease. Historically, high levels of protein kinase CK2 were linked with poor outcomes in head and neck squamous cell carcinoma (HNSCC), without consideration of HPV status. This retrospective study examined tumor $\mathrm{CK} 2 \alpha$ protein expression levels and related clinical outcomes in a cohort of Veteran OPSCC patient tumors which were determined to be predominantly HPV $(+)$. Methods. Patients at the Minneapolis VA Health Care System with newly diagnosed primary OPSCC from January 2005 to December 2015 were identified. 119 OPSCC patient tumors were stained for CK2 $\alpha$, p16 and Ki-67 proteins and E6/E7 RNA. CK2 $\alpha$ protein levels in tumors and correlations with HPV status and Ki-67 index were assessed. Overall survival (OS) analysis was performed stratified by CK2 $\alpha$ protein score and separately by HPV status, followed by Cox regression controlling for smoking status. To strengthen the limited HPV (-) data, survival analysis for HPV(-) HNSCC patients in the publicly available The Cancer Genome Atlas (TCGA) PanCancer RNA-seq dataset was determined for CSNK2A1. Results. The patients in the study population were all male and had a predominant history of tobacco and alcohol use. This cohort comprised $84 \mathrm{HPV}(+)$ and $35 \mathrm{HPV}(-)$ tumors. CK2 $\alpha$ levels were higher in $\mathrm{HPV}(+)$ tumors compared to $\mathrm{HPV}(-)$ tumors. Higher CK2 $\alpha$ scores positively correlated with higher Ki-67 index. OS improved with increasing CK2 $\alpha$ score and separately OS was significantly better for those with HPV $(+)$ as opposed to 
HPV(-) OPSCC. Both remained significant after controlling for smoking status. High CSNK2A1 mRNA levels from TCGA data associated with worse patient survival in HPV(-) HNSCC. Conclusions. High CK2 $\alpha$ protein levels are detected in HPV $(+)$ OPSCC tumors and demonstrate an unexpected association with improved survival in a strongly $\mathrm{HPV}(+)$ OPSCC cohort. Worse survival outcomes for high CSNK2A1 mRNA levels in HPV(-) HNSCC are consistent with historical data. Given these surprising findings and the rising incidence of $\operatorname{HPV}(+)$ OPSCC, further study is needed to understand the biological roles of CK2 in $\mathrm{HPV}(+)$ and $\mathrm{HPV}(-) \mathrm{HNSCC}$ and the potential utility for therapeutic targeting of CK2 in these two disease states. 
1 Identification of high protein kinase CK2 $\alpha$ in $\mathrm{HPV}(+)$ oropharyngeal

2 squamous cell carcinoma and correlation with clinical outcomes

4 Janeen H. Trembley $1,2,3, \#$; Bin Li ${ }^{4,5, \#, \& ; ~ B e t s y ~ T . ~ K r e n ~}{ }^{1,3}$; Justin Peltola ${ }^{2,6}$; Juan Manivel2,6; Devi

5 Meyyappan ${ }^{7,+}$; Amy Gravely ${ }^{1}$, Mark Klein ${ }^{3,7,8, *}$; Khalil Ahmed ${ }^{1,2,3,5, *}$, Emiro Caicedo-

6 Granados $3,4,5, *$

$7 \quad{ }^{1}$ Research Service, Minneapolis VA Health Care System, Minneapolis, MN, USA

8 2Department of Laboratory Medicine and Pathology, University of Minnesota, Minneapolis, MN,

9 USA

$10{ }^{3}$ Masonic Cancer Center, University of Minnesota, Minneapolis, MN, USA

$11{ }^{4}$ Otolaryngology Section, Minneapolis VA Health Care System, Minneapolis, MN, USA

12 5epartment of Otolaryngology, University of Minnesota, Minneapolis, MN, USA

$13{ }^{6}$ Laboratory Medicine and Pathology Service, Minneapolis VA Health Care System,

14 Minneapolis, MN, USA

$15{ }^{7}$ Hematology and Oncology Section, Minneapolis VA Health Care System, Minneapolis, MN,

16 USA

$17{ }^{8}$ Department of Medicine, University of Minnesota, Minneapolis, MN, USA

Running title: CK2 $\alpha$ expression in OPSCC

\#Equal contributions by authors

*Co-senior authors

\&Current address: Kaiser Permanente Roseville Medical Center, Department of Head and Neck Surgery, 1600 Eureka Rd, Medical Office Building D, Roseville, CA, 95661, USA

${ }^{+}$Current address: University of Texas Medical Branch, 301 University Blvd, Galveston, TX 77555, USA

Address Correspondence to: Janeen H. Trembley, trem0005@umn.edu 


\section{Abstract}

Background. Oropharyngeal squamous cell carcinoma (OPSCC) incidence is rising worldwide, especially human papillomavirus (HPV)-associated disease. Historically, high levels of protein kinase CK2 were linked with poor outcomes in head and neck squamous cell carcinoma (HNSCC), without consideration of HPV status. This retrospective study examined tumor CK2 $\alpha$ protein expression levels and related clinical outcomes in a cohort of Veteran OPSCC patient tumors which were determined to be predominantly $\operatorname{HPV}(+)$.

Methods. Patients at the Minneapolis VA Health Care System with newly diagnosed primary OPSCC from January 2005 to December 2015 were identified. 119 OPSCC patient tumors were stained for CK2 $\alpha$, p16 and Ki-67 proteins and E6/E7 RNA. CK2 $\alpha$ protein levels in tumors and correlations with HPV status and Ki-67 index were assessed. Overall survival (OS) analysis was performed stratified by CK $2 \alpha$ protein score and separately by HPV status, followed by Cox regression controlling for smoking status. To strengthen the limited $\mathrm{HPV}(-)$ data, survival analysis for HPV $(-)$ HNSCC patients in the publicly available The Cancer Genome Atlas (TCGA) PanCancer RNA-seq dataset was determined for CSNK2A1.

Results. The patients in the study population were all male and had a predominant history of tobacco and alcohol use. This cohort comprised $84 \mathrm{HPV}(+)$ and $35 \mathrm{HPV}(-)$ tumors. CK2 $\alpha$ levels were higher in $\mathrm{HPV}(+)$ tumors compared to $\mathrm{HPV}(-)$ tumors. Higher $\mathrm{CK} 2 \alpha$ scores positively correlated with higher Ki-67 index. OS improved with increasing CK2 $\alpha$ score and separately OS was significantly better for those with $\mathrm{HPV}(+)$ as opposed to $\mathrm{HPV}(-)$ OPSCC. Both remained significant after controlling for smoking status. High CSNK2A1 mRNA levels from TCGA data associated with worse patient survival in HPV(-) HNSCC.

Conclusions. High CK2 $\alpha$ protein levels are detected in $\mathrm{HPV}(+)$ OPSCC tumors and demonstrate an unexpected association with improved survival in a strongly $\mathrm{HPV}(+) \mathrm{OPSCC}$ cohort. Worse survival outcomes for high CSNK2A1 mRNA levels in HPV(-) HNSCC are consistent with historical data. Given these surprising findings and the rising incidence of $\mathrm{HPV}(+) \mathrm{OPSCC}$, further study is needed to understand the biological roles of CK2 in HPV $(+)$ and HPV $(-)$ HNSCC and the potential utility for therapeutic targeting of CK2 in these two disease states. 


\section{INTRODUCTION}

The majority of cancers that arise from the mucosal epithelium in the oral cavity, pharynx and larynx are grouped together as HNSCC. A critical categorization that has arisen in HNSCC is the presence or absence of HPV infection, and the bulk of $\mathrm{HPV}(+) \mathrm{HNSCC}$ derives from the oropharynx (oropharyngeal squamous cell carcinoma, OPSCC) (Fakhry et al. 2014; Johnson et al. 2020; Klein \& Grandis 2010; Pfister \& Fury 2014). In recent years, HPV-related OPSCC has been recognized as a unique entity that behaves differently from other HNSCC types connected with traditional carcinogens such as tobacco and alcohol. Notably, HPV $(+)$ OPSCC patients have significantly better overall survival and disease-free survival compared to their HPV(-) counterparts (Ang et al. 2010; Chaturvedi et al. 2011). HPV status was recently designated as a relevant biomarker, and detection of the cellular protein $\mathrm{p} 16^{\mathrm{INK} 4 \mathrm{~A}}(C D K N 2 A)$ serves as a surrogate marker for HPV positivity (Beltz et al. 2019; Johnson et al. 2020; Rosenthal et al. 2016). The malignant transformation of HPV infected cells involves inactivation of tumor suppressor proteins p53 and Rb by viral oncoproteins E6 and E7, respectively (Gillison et al. 2000; Rampias et al. 2009). The HPV-encoded E6 and E7 RNAs can be detected in tumor tissue to indicate HPV infection.

Protein kinase CK2 is a ubiquitous and highly conserved protein serine/threonine kinase that promotes cell growth and cell proliferation and also suppresses apoptosis. CK2 is a heterotetrameric enzyme consisting of two catalytic $\alpha$ and $\alpha^{\prime}$ subunits linked via two regulatory $\beta$ subunits, and these proteins localize to both the cytoplasmic and nuclear compartments (Faust et al. 1999). Numerous CK2 substrates have been identified indicating its involvement in a large number of cellular activities (Borgo et al. 2021). Further, multiple important cellular signaling pathways are affected by CK2 activity, including, but not limited to, NFкB, AKT, TP53, Wnt/ $\beta$ - 
83 catenin and PTEN (Dominguez, Sonenshein \& Seldin 2009; Ruzzene \& Pinna 2010; Trembley et 84 al. 2010).

85 CK2 has been found to be elevated relative to normal tissue in nearly all cancer types, 86 including head and neck squamous cell carcinoma (HNSCC) in general as well as OPSCC

87 (Chua, Lee \& Dominguez 2017; Trembley et al. 2009). Previous studies established that elevated

88 CK2 activity or levels in head and neck cancer are associated with Ki-67-positive tumor cells, 89 aggressive tumor behavior and poor clinical outcome (Chua, Lee \& Dominguez 2017; Faust et al. 1996; Faust et al. 1999; Gapany et al. 1995); however, these studies did not incorporate tumor HPV status. CK2 phosphorylates and/or regulates HPV proteins such as E1 and E7 and cellular proteins such as Brd4 to exert influence over HPV DNA replication and cellular proliferation (Basukala et al. 2019; Firzlaff et al. 1989; Iftner et al. 2017; Piirsoo et al. 2019; Zine El Abidine et al. 2017). Therefore, we postulate that CK2 is likely to play a role in the pathogenesis of HPVrelated HNSCC and may potentially influence tumor behavior.

To our knowledge, this is the first report on the expression of CK2 $\alpha$ in $\mathrm{HPV}(+)$ OPSCC tumors. In the present retrospective study we examined tumor CK2 $\alpha$ and Ki-67 protein levels and HPV status. First, we describe the relationships between CK2 $\alpha$ protein levels in tumors and patient characteristics, HPV status, and Ki-67 index. We present overall survival (OS) analyses stratified by CK2 $\alpha$ protein level and separately by HPV status. We examine other univariate relationships with survival to identify covariates to control for in our two main analyses of interest. Finally, we evaluated survival outcomes in HPV(-) HNSCC using The Cancer Genome Atlas (TCGA) RNA-seq data.

\subsection{Patients}


107 The study was conducted according to the guidelines of the Declaration of Helsinki, and

108 approved by the Institutional Review Board of Minneapolis VA Health Care System (4632-A,

109 approved June 6, 2016). Patient consent was waived by the Institutional Review Board due to the

110 retrospective nature of the study. Data analysis was completed under an approved Research and

111 Development Committee protocol (VAM-20-00609, approved July 17, 2020).

112 For this retrospective cohort study, a database search was performed in the tumor registry

113 for the Minneapolis Veterans Affairs Healthcare System. All patients with newly diagnosed

114 primary OPSCC from January 2005 to December 2015 were identified. Inclusion criteria were 1)

115 biopsy-proven primary OPSCC, and 2) adequate tissue in archived tissue bank to perform

116 immunohistochemical (IHC) staining. Patients who had other simultaneous active malignancy at

117 the time of diagnosis or lacked follow up were excluded. Patient demographics including age at

118 diagnosis, gender, smoking history, and alcohol consumption history were recorded. Tumor

119 characteristics including primary subsite, tumor stage, and treatment modalities were reviewed

120 from patient charts. Clinical outcomes including disease progression and death were also

121 recorded. Patients were censored at the end of this study.

$122 \quad 2.2$ p16, Ki-67 and CK2 IHC stain

123 Formalin-fixed paraffin-embedded (FFPE) tissue blocks were retrieved from the pathology tissue

124 archive. IHC stain was performed with Bond Refine Polymer Detection Kit on the Bond III

125 Automated Stainer (Leica Biosystems, Buffalo Grove, IL, USA), with the following primary

126 antibodies: mouse monoclonal anti-p16 antibody E6H4 (Ventana Medical Systems, Oro Valley,

127 AZ, USA), rabbit monoclonal anti-Ki-67 antibody SP6 (Cell Marque, Sigma-Aldrich, Rocklin,

128 CA, USA), and rabbit monoclonal anti-CK2 alpha antibody ab76040 (Abcam, Cambridge,

129 United Kingdom). Positive p16 expression was defined as greater than $70 \%$ of tumor cells with 
130 strong nuclear and cytoplasmic staining. Reactivity for Ki-67 was evaluated as percentage of

131 viable tumor nuclei positive for this marker.

132 CK2 $\alpha$ staining was verified using myometrium for the "negative" control which showed

133 a very low level staining and using testicle as the positive control as it has a high level of CK2.

134 For further negative control, the CK2 $\alpha$ primary antibody was substituted with appropriate isotype

135 control antibody ab172730 (Abcam). Specificity of CK2 $\alpha$ staining was tested by comparing

$136 \mathrm{CK} 2 \alpha$ antibody to isotype control in sequential sections from five OPSCC tumors with CK2 $\alpha$

137 score of 3 and five OPSCC tumors with CK2 $\alpha$ score of 1 . CK2 $\alpha$ scoring was evaluated by semi-

138 quantitative assessment of the relative antigen density in combined cytoplasm and nucleus of

139 viable tumor cells (Zhou et al. 2014). Reactivity was evaluated as score 3 (intense), score 2

140 (moderate), score 1 (weak), and score 0 (no staining). All scoring and expression levels were

141 evaluated and agreed upon by two staff pathologists (J.P. and J.C.M.).

$142 \quad 2.3$ E6 and E7 RNA in situ hybridization stain

143 E6 and E7 mRNA of HPV16/18 were detected in tumor sections using the Bond RNAscope kit

144 and following the Leica RNAscope DAB in situ hybridization protocol (*RS_DAB, Leica

145 Biosystems). Processing was performed using the Automated Stainer instrument.

\section{2.4 Definition of HPV status}

147 To obtain unambiguous information on the HPV status in these tumors, they were stained for

148 cellular p16 ${ }^{\mathrm{INK} 4 \mathrm{a}}$, commonly used as a surrogate marker for HPV positivity, and for the HPV

149 RNAs E6 and E7. P16 was positive in 70.3\% of patients and E6/E7 RNAs were detected in

$15070.6 \%$ of patients. Two patient tumors were p16-positive and E6/E7 RNA-negative; conversely,

1512 tumors were E6/E7 RNA-positive and p16-negative. As expected, the relationship between p16

152 and E6/E7 detection in tumors was significant $(\mathrm{P}<0.0001)$. In the remainder of this study, 
153 positive E6/E7 detection in tumors was used as our operational definition of HPV(+) vs. HPV(-)

154 status, including those patients with discordant p16 results.

1552.5 Human HNSCC TCGA data analysis

156 Analysis of survival associated with CSNK2A1 mRNA levels in HNSCC HPV(-) patient

157 samples was performed via cBioPortal using the PanCancer Atlas data set from The Cancer

158 Genome Atlas ( $\mathrm{n}=415 \mathrm{HPV}(-)$ samples for OS and PFS; $\mathrm{n}=394$ for DSS; 23 September 2021).

159 For mRNA expression data, TCGA typically computes the relative expression of an individual

160 gene in a tumor sample to the gene's expression distribution in a reference population of samples.

161 In this analysis, the reference set was all samples that are diploid for CSNK2A1. The returned

162 value indicates the number of standard deviations away from the mean of expression in the

163 reference population (Z-score) Z-score cut-off was set at $>+1.5$ higher expression of CSNK2A1

164 compared to unaltered or lower levels of CSNK2A1.

\section{$165 \quad 2.6$ Statistical analysis}

166 In Table 1, we utilize counts and proportions for categorical variables to describe the sample.

167 We present descriptive data overall and examine the relationships between CK2 score category

168 and the variables HPV status or Ki-67. Analyses for Table 2 included Pearson's chi-square test

169 for categorical variables or Fisher's exact test where any cell size was less than 5. The chi-square

170 test for independence was used to test the relationship between positive detection of E6/E7 RNA

171 and of p16. We defined statistical significance by $P$ value $<0.05$. The analyses were performed

172 in SAS $9.4{ }^{\circledR}$ software.

$173 \quad$ 2.7 Survival analysis

174 Utilizing the Veterans cohort dataset, univariate Cox regression was performed for clinical

175 variables CK2 $\alpha$ and HPV status (predictors of interest) and for co-variates Ki-67, treatment, age, 
176 alcohol, smoking, T and N classifications, and clinical stage ( $7^{\text {th }}$ edition of the AJCC cancer

177 staging manual) to explore if any of these should be controlled for in our main two survival

178 analyses of interest (Table 3). As our main analysis of interest, OS was stratified by HPV and

179 separately by CK2 $\alpha$. Survival curves for OS according to CK2 $\alpha$ score and separately for HPV

180 status were fitted using the Kaplan-Meier method. Log rank P-values are presented. Since

181 smoking status (current vs. never or former) was significant by univariate analysis, we

182 additionally controlled for this in multivariate Cox regressions. OS time was defined as from

183 treatment initiation to death. PFS time was defined as from treatment initiation to disease

184 progression or death. These analyses were performed in SAS $9.4{ }^{\circledR}$ software. Analyses using the

185 TCGA cohort dataset were performed using cBioPortal. A P-value of 0.05 was utilized to denote

186 statistical significance.

187

1883 RESULTS

$189 \quad 3.1$ Patient and tumor characteristics overall

190 A total of 147 patients at the Minneapolis VA hospital between 2005 and 2015 met the inclusion 191 criteria, and sufficient tumor tissue was available for analysis in 119 patients. The mean age of 192 diagnosis for all patients, as well as the $\mathrm{HPV}(+)$ and $\mathrm{HPV}(-)$ subgroups, was 63 years. The 193 diagnosis age range for $\mathrm{HPV}(+)$ was 44 to 88 years, and for $\mathrm{HPV}(-)$ was 53 to 82 years. As 194 shown in Table 1, the majority of the patients had a history of smoking $(94.1 \%)$ and alcohol use 195 (84.0\%). The most common subsite of OPSCC was tonsil $(58.6 \%)$, followed by base of tongue 196 (35.3\%). The majority of the patients presented with stage IV disease (70.6\%) according to the $1977^{\text {th }}$ edition of the AJCC cancer staging manual. All tumors were conventional type squamous cell 198 carcinoma histology. 
199 All patients received treatment compliant with NCCN guidelines and with curative intent. Our

200 data show that $70 \%$ of patients completed treatment for all modalities. Breaking down the

201 different treatment groups shown in Table 1, the percentages of patients that completed the full

202 treatment regimen are as follows: Surgery 100\%, Radiation 75\%, CCRT 68\%, Surgery/Radiation

$20383 \%$, and Surgery/CCRT 50\%.

$204 \quad 3.2$ CK2 $\alpha$ staining and association with patient characteristics

205 Tumors were stained for CK2 $\alpha$ protein, and CK2 $\alpha$ scoring was evaluated by semi-quantitative

206 assessment of the relative antigen density in combined cytoplasm and nucleus of viable tumor

207 cells. Reactivity was evaluated as score 3 (intense), score 2 (moderate), score 1 (weak), and score

2080 (no staining). As expected, due to ubiquitous expression of CK2 $\alpha$ in most cancer cells, no

209 scores of 0 were observed for CK $2 \alpha$. Representative images of CK2 $\alpha$ score 1, 2 and 3 with

210 corresponding H\&E and Ki-67 stains are depicted in Fig. 1. The percentage of patients with

211 CK2 $\alpha$ tumor score of 1,2 and 3 were $23.5 \%, 50.4 \%$ and $26.1 \%$, respectively. Age at diagnosis,

212 alcohol use, $\mathrm{T}$ or $\mathrm{N}$ classification, or treatment modality did not differ significantly between

213 CK2 $\alpha$ score categories. The majority of stage I tumors had CK2 $\alpha$ score of 1.

214 3.3 Evaluation of CK2 $\alpha$ protein levels in tumors and correlations with HPV status and Ki-

21567 index

$216 \mathrm{HPV}(+)$ tumors, as defined by positive detection of E6/E7 RNA, represented 21.4\% of CK2 $\alpha$

217 score 1 tumors, $83.3 \%$ of CK $2 \alpha$ score 2 tumors, and $90.3 \%$ of CK $2 \alpha$ score 3 tumors. We

218 examined whether CK2 $\alpha$ expression levels and HPV positivity were associated. As shown in

219 Table 2, CK2 $\alpha$ score strongly corresponded with HPV $(+)$ OPSCC $(\mathrm{P}<0.0001)$.

220 Given the different mutational and HPV statuses of these malignancies, we were also

221 interested in the proliferative state of these tumors and thus performed Ki-67 staining and 
222 analysis. We found that the tumors in this entire cohort were highly proliferative, with $72.3 \%$ of

223 tumor cells more than $20 \%$ positive for Ki-67. In analysis of CK2 $\alpha$ scores with the Ki-67 index

224 in tumors, there was a positive relation of higher CK2 $\alpha$ score with higher percentage of Ki-67

225 positivity $(\mathrm{P}<0.0003$; Table 2$)$.

\section{$226 \quad 3.4$ Survival analysis}

227 PFS rates and OS rates among the CK2 $\alpha$ scores were very similar, and we focused on analysis of

228 OS. Univariate Cox regression analysis for OS was performed for the two independent variables

229 of interest CK2 $\alpha$ and HPV and the potential co-variates Ki-67, treatment, age, alcohol, smoking,

230 TNM stage, and clinical classification ( $7^{\text {th }}$ edition of the AJCC staging classification) to

231 investigate their association with survival time of patients and potential to be entered into

232 multivariate Cox regression (Table 3). The relationships CK2 $\alpha$ (high score of 2 or 3 vs. low score

233 of 1) and HPV status (independent variables of interest) and co-variate smoking (current vs.

234 former or never) were all statistically significant. Kaplan-Meier analysis comparing the three

235 CK2 $\alpha$ scores in all patients showed that OS was significantly different with improved OS as

236 CK2 $\alpha$ score increased (Fig. 2A). Kaplan-Meier analysis by HPV status (positive vs. negative) in

237 all patients demonstrated significantly better OS for HPV(+) OPSCC (Fig. 2B).

238

Because the co-variate smoking was significant in univariate analysis, we controlled for

smoking in two separate multivariate Cox regressions for the predictors CK2 $\alpha$ or HPV. CK2 $\alpha$

240 level (high score of 2 or 3 vs. low score of 1) or HPV status (negative vs. positive) remained

241 statistically significant after controlling for smoking (CK2 $\alpha$ HR $0.461[0.246,0.867], \mathrm{P}=$

242 0.0162; HPV HR $2.567[1.329,4.959], \mathrm{P}=0.0050)$. 
244 Our group of HPV(-) OPSCC patients is limited, but previous studies suggest that high CK2

245 levels $\left(\alpha, \alpha^{\prime}, \beta\right)$ in the context of HPV(-) disease are a risk for worse outcomes(Chua et al. 2017;

246 Faust et al. 1996; Gapany et al. 1995). Because the number of patients with HPV(-) disease was

247 low in our cohort, we analyzed the publicly available TCGA HNSCC PanCancer RNA-seq data

248 using cBioportal (Cerami et al. 2012; Gao et al. 2013). Disease-specific survival analysis was

249 performed in the HPV(-) cohort comparing high CSNK2A1 (CK2 $\alpha$ ) mRNA levels (Z-score cut-

250 off $>1.5, \mathrm{n}=117)$ to unaltered or low CSNK2A1 mRNA (n = 277). In HPV $(-)$ HNSCC, high

251 CSNK2A1 mRNA levels associated with significantly worse survival $(\log \operatorname{rank} \mathrm{P}=0.0279 ; \mathrm{q}=$

252 0.0478; Fig. 3). PFS and OS were also significantly worse for high CSNK2A1 (logrank $\mathrm{P}=$

2530.0314 and $\mathrm{P}=0.0359$, respectively; $\mathrm{q}=0.0478$ for both PFS and OS $)$. In the HPV $(+)$ cohort, the

254 subset of patients with high $C S N K 2 A 1$ mRNA tumors consisted of only 7 tumors relative to 56

255 tumors with unaltered $C S N K 2 A 1$; there was insufficient survival data in the CSNK2A1 high

256 group for analysis.

\section{DISCUSSION}

258 In the present work, we have discovered an unexpected difference in the CK2-related survival of

$259 \mathrm{HPV}(+)$ compared with HPV(-) HNSCC. This novel aspect is discussed as follows. clinical outcome in various types of malignancies, including HNSCC (Chua, Lee \& Dominguez 2017; Faust et al. 1996; Gapany et al. 1995; Kim et al. 2007; Laramas et al. 2007; Li et al. 2017; Lin et al. 2010; Lin et al. 2011; O-Charoenrat et al. 2004). In these earlier studies, HPV status was not evaluated in the context of CK2 activity. As the current increase in OPSCC incidence is considerably linked to HPV presence, we undertook this examination of CK2 level and patient outcomes in relation to HPV status. Using RNA-seq data from The Cancer Genome Atlas 
267 (TCGA), we found that high CSNK2A1 (CK2 $\alpha$ ) mRNA levels associate with worse disease-

268 specific survival, PFS, and OS in HPV(-) HNSCC. Protein and mRNA abundances roughly

269 correlate in cells and tissue, and CSNK2A1 mRNA levels are significantly elevated in OPSCC

270 (Chua, Lee \& Dominguez 2017; Schwanhäusser et al. 2011). Thus, these HPV negative-specific

271 RNA-based data support previous findings that high CK2 levels associate with poor prognosis

272 and survival outcomes in non-HPV related cancers.

In contrast to the above discussion, in this study we found that high CK2 $\alpha$ protein level was not associated with worse survival in OPSCC. Rather, in a cohort of OPSCC patients with predominantly $\mathrm{HPV}(+)$ disease, we found that high CK2 $\alpha$ abundance associated with improved survival outcome. It is well documented that $\mathrm{HPV}(+)$ OPSCC patients have improved survival, and the data show that high CK2 $\alpha$ protein levels are present in the tumors of HPV $(+)$ OPSCC patients. These are interesting indications that CK2 may play specialized roles in $\operatorname{HPV}(+)$ HNSCC, and accord with published information on CK2 regulation of papillomavirus lifecycle. infected cells through inactivation of $\mathrm{p} 53$ and $\mathrm{pRb}$ and related pathway proteins, respectively (Eckhardt et al. 2018). Previous studies demonstrated key regulation of E7 function by CK2 (Basukala et al. 2019; Firzlaff et al. 1989; Nogueira et al. 2017; Zine El Abidine et al. 2017). For example, the phosphorylation of E7 by $\mathrm{CK} 2$ is essential to promote Rb-related p130 degradation and cell cycle S-phase entry (Chien et al. 2000; Genovese et al. 2008). CK2 $\alpha$ is required for HPV DNA replication by regulating the stability and nuclear retention of E1, and CK2 has been proposed as a promising target for the development of anti-viral drugs, including SARS-CoV-2 (Bouhaddou et al. 2020; Cruz et al. 2021; Piirsoo et al. 2019). It has been shown that targeting of CK2 activity using an investigational peptide inhibitor is effective in treating cervical cancer, 
290 which is almost entirely $\mathrm{HPV}(+)$ (Sarduy et al. 2015; Solares et al. 2009). This CK2 inhibitor,

291 CIGB-300, was identified in a screen of peptides which bind and block phosphorylation of an

292 HPV16 E7 fusion protein (Perea et al. 2004).

293

294

295

296

297

298

299

300

301

302

303

304

305

306

307

308

309

310

311

312

Our observation of better OS in $\mathrm{HPV}(+)$ OPSCC is consistent with previous reports (Ang et al. 2010; Chaturvedi et al. 2011). At present, how the higher HPV viral load and viral oncoprotein function correlate with improved patient survival in OPSCC remains unclear (Cohen et al. 2008). Here we report high $\mathrm{CK} 2 \alpha$ levels associate with improved survival in OPSCC, using a cohort of patients with predominance of $\operatorname{HPV}(+)$ disease. In our cohort of patients, a high percentage of $\mathrm{HPV}(+)$ patients were observed in the high CK2 $\alpha$ score subgroups (score of 2 or 3). These associations raise the question on the potential cross-regulatory nature of HPV and CK2 interactions. It is unknown if active HPV infection and the downstream effectors have an impact on the level or activity of CK2 itself in OPSCC. We posit that, under conditions of HPV infection, CK2 protein levels rise and that viral and/or cellular protein complexes could divert the function of CK2 proteins to promote the HPV lifecycle as opposed to other pro-survival cancer cell roles.

There is no literature in head and neck cancer investigating CK2 in relation to smoking or alcohol. Our results demonstrated that CK2 $\alpha$ level and HPV status remained significant to OS after controlling for smoking as a covariate. In this analysis, we controlled for current smokers vs. former/never smokers, which is an important distinction for survival in this disease. The validity of this preliminary finding would require testing on a more heterogeneous patient population in terms of smoking history as $94 \%$ of our VA population were former or current smokers. Use of alcohol and tobacco are known factors contributing to worse outcomes in both $\mathrm{HPV}(+)$ and $\mathrm{HPV}(-) \mathrm{HNSCC}$; however, there are conflicting data. Large-scale clinical trials 
313 reported tobacco exposure to be an important prognostic factor, independent of HPV status (Ang

314 et al. 2010; Gillison et al. 2012). A recent HPV-blind study using data from the entire VHA

315 health care system from 2000 to 2012 reported significantly worse 2-year OS in ever-smoker

316 Veterans compared to never-smoker Veterans (Zevallos 2021). Another study observed that

317 HPV $(+)$ status did not confer better survival in smokers (Hafkamp et al. 2008). Two reports in

3182015 showed better survival in p16(+) Veterans, despite the high tobacco and alcohol use

319 (Sandulache et al. 2015; Shay et al. 2015). Further understanding of HPV(+) OPSCC biology

320 and outcomes in the Veterans population is needed (Sandulache et al. 2020).

321 For this observational retrospective study, the potential influences of bias or confounders

322 on the results need to be considered. The patients in the study population were Veterans, all from

323 the same hospital, all male, and had a predominant history of tobacco and alcohol use. Lifestyle,

324 and systematic differences between $\mathrm{HPV}(+)$ and $\mathrm{HPV}(-)$ patients and their treatment regimens

325 are not factors incorporated in the analysis of this study, and these factors could be contributors

326 to OS. Therefore, the findings in this study may not be fully applicable to women or the general

327 population. Similarly, patients who received surgery as the only modality of treatment had lower

328 stage of disease (small primary tumor and small neck lymph nodes), therefore comparison of

329 surgery alone to other treatment modalities incorporates bias in the survival analysis. The

330 relatively small sample size in the $\mathrm{HPV}(+) / \mathrm{CK} 2 \alpha$ score 1 subgroup and in the entire $\mathrm{HPV}(-)$

331 cohort limited the statistical power of the study. We acknowledge these potential confounders in

332 the interpretation of this data.

\section{Conclusions}

334 The increasing prevalence of HPV-associated head and neck cancers underpins the need to 335 understand their biology and related outcomes. To our knowledge, this is the first report 
336 evaluating CK2 $\alpha$ expression level and its correlation with either HPV status or survival outcomes

337 in OPSCC patients. CK2 $\alpha$ protein levels showed direct positive correlation with HPV positivity.

338 Unexpectedly, high CK2 $\alpha$ levels were associated with significantly improved survival in all

339 OPSCC patients, where more than $70 \%$ of the cases were $\operatorname{HPV}(+)$. Overall, our data demonstrate

340 a surprising and intriguing association between $\mathrm{CK} 2 \alpha$ expression in $\mathrm{HPV}(+)$ OPSCC and

341 survival; further studies are necessary to determine if this association has prognostic value. Phase

3421 and 2 clinical trials have demonstrated that the oral CK2 inhibitor Silmitasertib/CX-4945 is

343 safe for use in cancer patients, slowing disease progression and extending treatment benefit for

344 some patients with advanced solid tumor cancers. In cultured cells, we have shown that CX-4945

345 is an effective treatment alone and in combination with cisplatin in both $\operatorname{HPV}(+)$ and $\operatorname{HPV}(-)$

346 HNSCC (Trembley et al. 2021). Given the high levels of CK2 $\alpha$ protein in HPV(+) tumors as

347 well as the association of high CK2 $\alpha$ mRNA levels with poor outcomes in HPV(-) patients, our

348 results suggest that future investigation into the incorporation of CX-4945 into treatment

349 strategies is warranted. In addition, the function of CK2 in HPV biology as it pertains to HNSCC

350 requires further study given the emergence of $\mathrm{HPV}(+) \mathrm{HNSCC}$.

\section{Acknowledgments}

353 K.A. holds the title of Senior Research Career Scientist awarded by the U.S. Department of

354 Veterans Affairs. We thank VA Pathology Service members Wendy Larson and Sue Dachel for 355 technical assistance.

\section{Human Ethics}

357 The study was conducted according to the guidelines of the Declaration of Helsinki, and approved by the Institutional Review Board of Minneapolis VA Health Care System (4632-A, 
359 approved June 6, 2016). Patient consent was waived by the Institutional Review Board due to the

360 retrospective nature of the study. Data analysis was completed under an approved Research and

361 Development Committee protocol (VAM-20-00609, approved July 17, 2020).

362 Data Availability

363 The raw data are available in the Supplementary Files.

364 Supplemental Information

365 Supplemental information for this article can be found online

366 Disclaimer

367 The contents do not represent the views of the U.S. Department of Veterans Affairs or the United 368 States government.

369 
370

371

372

373

374

375

376

377

378

379

380

381

382

383

384

385

386

\section{FIGURE LEGENDS}

Figure 1. Expression of CK2 $\alpha$ in OPSCC tumors. (A) Representative field following CK $2 \alpha$ versus isotype control antibody IHC stain in OPSCC tumor tissue is shown. CK2 $\alpha$ was detected by DAB (brown). Blue depicts nuclei. Identity of staining antibody is indicated below each panel. Scale bar, $100 \mu \mathrm{m}$. (B) Representative fields of CK2 $\alpha$ IHC stain in OPSCC tumor tissues are shown with corresponding $\mathrm{H} \& \mathrm{E}$ and $\mathrm{Ki}-67$ stain in the same tumors. $\mathrm{CK} 2 \alpha$ and $\mathrm{Ki}-67$ were detected by DAB (brown). Blue depicts nuclei. Identity of stain is indicated at the left and CK2 $\alpha$ score is indicated above the panels. H\&E, hematoxylin and eosin. Scale bar, $100 \mu \mathrm{m}$.

Figure 2. Survival curves based on CK2 $\alpha$ scores or HPV status in Minneapolis VA cohort. Kaplan-Meier survival curves are shown. (A) OS according to CK2 $\alpha$ score. (B) OS according to HPV status. The legend identifying each survival curve line is indicated below each chart.

Figure 3. Disease-specific survival based on CSNK2A1 mRNA levels in HPV(-) HNSCC. Kaplan-Meier survival curve is shown for CSNK2A1 (CK2 $\alpha)$ mRNA z-scores in HPV(-) HNSCC patients from TCGA RNA-seq data. The legend is indicated below the chart. 
387

388

389

390

391

392

393

394

395

396

397

398

399

400

401

402

403

404

405

406

407

408

409

410

411

412

413

414

415

416

417

418

419

420

421

422

423

424

425

426

427

428

429

430

431

432

\section{REFERENCES}

Ang KK, Harris J, Wheeler R, Weber R, Rosenthal DI, Nguyen-Tan PF, Westra WH, Chung CH, Jordan RC, Lu C, Kim H, Axelrod R, Silverman CC, Redmond KP, and Gillison ML. 2010. Human papillomavirus and survival of patients with oropharyngeal cancer. N Engl J Med 363:24-35. 10.1056/NEJMoa0912217

Basukala O, Mittal S, Massimi P, Bestagno M, and Banks L. 2019. The HPV-18 E7 CKII phospho acceptor site is required for maintaining the transformed phenotype of cervical tumour-derived cells. PLoS pathogens 15:e1007769. 10.1371/journal.ppat.1007769

Beltz A, Gösswein D, Zimmer S, Limburg I, Wünsch D, Gribko A, Deichelbohrer M, Hagemann J, Stauber $\mathrm{RH}$, and Künzel J. 2019. Staging of oropharyngeal squamous cell carcinoma of the head and neck: Prognostic features and power of the 8th edition of the UICC staging manual. European Journal of Surgical Oncology 45:1046-1053. https://doi.org/10.1016/j.ejso.2019.02.032

Borgo C, D'Amore C, Sarno S, Salvi M, and Ruzzene M. 2021. Protein kinase CK2: a potential therapeutic target for diverse human diseases. Signal Transduction and Targeted Therapy 6:183. 10.1038/s41392-021-00567-7

Bouhaddou M, Memon D, Meyer B, White KM, Rezelj VV, Correa Marrero M, Polacco BJ, Melnyk JE, Ulferts S, Kaake RM, Batra J, Richards AL, Stevenson E, Gordon DE, Rojc A, Obernier K, Fabius JM, Soucheray M, Miorin L, Moreno E, Koh C, Tran QD, Hardy A, Robinot R, Vallet T, Nilsson-Payant BE, Hernandez-Armenta C, Dunham A, Weigang S, Knerr J, Modak M, Quintero D, Zhou Y, Dugourd A, Valdeolivas A, Patil T, Li Q, Hüttenhain R, Cakir M, Muralidharan M, Kim M, Jang G, Tutuncuoglu B, Hiatt J, Guo JZ, Xu J, Bouhaddou S, Mathy CJP, Gaulton A, Manners EJ, Félix E, Shi Y, Goff M, Lim JK, McBride T, O'Neal MC, Cai Y, Chang JCJ, Broadhurst DJ, Klippsten S, De wit E, Leach AR, Kortemme T, Shoichet B, Ott M, Saez-Rodriguez J, tenOever BR, Mullins RD, Fischer ER, Kochs G, Grosse R, García-Sastre A, Vignuzzi M, Johnson JR, Shokat KM, Swaney DL, Beltrao $\mathrm{P}$, and Krogan NJ. 2020. The Global Phosphorylation Landscape of SARS-CoV-2 Infection. Cell 182:685-712.e619. 10.1016/j.cell.2020.06.034

Cerami E, Gao J, Dogrusoz U, Gross BE, Sumer SO, Aksoy BA, Jacobsen A, Byrne CJ, Heuer ML, Larsson E, Antipin Y, Reva B, Goldberg AP, Sander C, and Schultz N. 2012. The cBio Cancer Genomics Portal: An Open Platform for Exploring Multidimensional Cancer Genomics Data. Cancer Discovery 2:401-404. 10.1158/2159-8290.cd-12-0095

Chaturvedi AK, Engels EA, Pfeiffer RM, Hernandez BY, Xiao W, Kim E, Jiang B, Goodman MT, Sibug-Saber M, Cozen W, Liu L, Lynch CF, Wentzensen N, Jordan RC, Altekruse S, Anderson WF, Rosenberg PS, and Gillison ML. 2011. Human Papillomavirus and Rising Oropharyngeal Cancer Incidence in the United States. Journal of Clinical Oncology 29:4294-4301. 10.1200/jco.2011.36.4596

Chien WM, Parker JN, Schmidt-Grimminger DC, Broker TR, and Chow LT. 2000. Casein kinase II phosphorylation of the human papillomavirus-18 E7 protein is critical for promoting S-phase entry. Cell growth \& differentiation : the molecular biology journal of the American Association for Cancer Research 11:425-435.

Chua MM, Ortega CE, Sheikh A, Lee M, Abdul-Rassoul H, Hartshorn KL, and Dominguez I. 2017. CK2 in Cancer: Cellular and Biochemical Mechanisms and Potential Therapeutic Target. Pharmaceuticals (Basel) 10. 10.3390/ph10010018

Chua MMJ, Lee M, and Dominguez I. 2017. Cancer-type dependent expression of CK2 transcripts. PloS one 12:e0188854. 10.1371/journal.pone.0188854

Cohen MA, Basha SR, Reichenbach DK, Robertson E, and Sewell DA. 2008. Increased viral load correlates with improved survival in HPV-16-associated tonsil carcinoma patients. Acta oto-laryngologica 128:583-589. 10.1080/00016480701558880 
433

434

435

436

437

438

439

440

441

442

443

444

445

446

447

448

449

450

451

452

453

454

455

456

457

458

459

460

461

462

463

464

465

466

467

468

469

470

471

472

473

474

475

476

477

478

479

Cruz LR, Baladrón I, Rittoles A, Díaz PA, Valenzuela C, Santana R, Vázquez MM, García A, Chacón D, Thompson D, Perera G, González A, Reyes R, Torres L, Pérez J, Valido Y, Rodriguez R, VázquezBloomquist DM, Rosales M, Ramón AC, Pérez GV, Guillén G, Muzio V, Perera Y, and Perea SE. 2021. Treatment with an Anti-CK2 Synthetic Peptide Improves Clinical Response in COVID-19 Patients with Pneumonia. A Randomized and Controlled Clinical Trial. ACS Pharmacol Transl Sci 4:206-212. 10.1021/acsptsci.0c00175

Dominguez I, Sonenshein GE, and Seldin DC. 2009. Protein kinase CK2 in health and disease: CK2 and its role in Wnt and NF-kappaB signaling: linking development and cancer. Cellular and Molecular Life Sciences 66:1850-1857. 10.1007/s00018-009-9153-z

Eckhardt M, Zhang W, Gross AM, Von Dollen J, Johnson JR, Franks-Skiba KE, Swaney DL, Johnson TL, Jang GM, Shah PS, Brand TM, Archambault J, Kreisberg JF, Grandis JR, Ideker T, and Krogan NJ. 2018. Multiple Routes to Oncogenesis Are Promoted by the Human Papillomavirus-Host Protein Network. Cancer Discov 8:1474-1489. 10.1158/2159-8290.Cd-17-1018

Fakhry C, Zhang Q, Nguyen-Tan PF, Rosenthal D, El-Naggar A, Garden AS, Soulieres D, Trotti A, Avizonis V, Ridge JA, Harris J, Le Q-T, and Gillison M. 2014. Human Papillomavirus and Overall Survival After Progression of Oropharyngeal Squamous Cell Carcinoma. Journal of Clinical Oncology 32:3365-3373. 10.1200/jco.2014.55.1937

Faust RA, Gapany M, Tristani P, Davis A, Adams GL, and Ahmed K. 1996. Elevated protein kinase CK2 activity in chromatin of head and neck tumors: association with malignant transformation. Cancer Lett 101:31-35. 10.1016/0304-3835(96)04110-9

Faust RA, Niehans G, Gapany M, Hoistad D, Knapp D, Cherwitz D, Davis A, Adams GL, and Ahmed K. 1999. Subcellular immunolocalization of protein kinase CK2 in normal and carcinoma cells. Int J Biochem Cell Biol 31:941-949. 10.1016/S1357-2725(99)00050-3

Firzlaff JM, Galloway DA, Eisenman RN, and Luscher B. 1989. The E7 protein of human papillomavirus type 16 is phosphorylated by casein kinase II. New Biol 1:44-53.

Gao J, Aksoy BA, Dogrusoz U, Dresdner G, Gross B, Sumer SO, Sun Y, Jacobsen A, Sinha R, Larsson E, Cerami E, Sander C, and Schultz N. 2013. Integrative Analysis of Complex Cancer Genomics and Clinical Profiles Using the cBioPortal. Science signaling 6:pl1-pl1. 10.1126/scisignal.2004088

Gapany M, Faust RA, Tawfic S, Davis A, Adams GL, and Ahmed K. 1995. Association of elevated protein kinase CK2 activity with aggressive behavior of squamous cell carcinoma of the head and neck. Mol Med 1:659-666.

Genovese NJ, Banerjee NS, Broker TR, and Chow LT. 2008. Casein kinase II motif-dependent phosphorylation of human papillomavirus E7 protein promotes p130 degradation and S-phase induction in differentiated human keratinocytes. Journal of virology 82:4862-4873. 10.1128/JVI.01202-07

Gillison ML, Koch WM, Capone RB, Spafford M, Westra WH, Wu L, Zahurak ML, Daniel RW, Viglione M, Symer DE, Shah KV, and Sidransky D. 2000. Evidence for a causal association between human papillomavirus and a subset of head and neck cancers. J Natl Cancer Inst 92:709-720. 10.1093/jnci/92.9.709

Gillison ML, Zhang Q, Jordan R, Xiao W, Westra WH, Trotti A, Spencer S, Harris J, Chung CH, and Ang KK. 2012. Tobacco smoking and increased risk of death and progression for patients with p16positive and p16-negative oropharyngeal cancer. J Clin Oncol 30:2102-2111. 10.1200/JCO.2011.38.4099

Hafkamp HC, Manni JJ, Haesevoets A, Voogd AC, Schepers M, Bot FJ, Hopman AHN, Ramaekers FCS, and Speel E-JM. 2008. Marked differences in survival rate between smokers and nonsmokers with HPV 16-associated tonsillar carcinomas. International Journal of Cancer 122:2656-2664. $10.1002 / \mathrm{ijc} .23458$

Peer) reviewing PDF | (2021:08:65093:2:0:NEW 22 Oct 2021) 
480

481

482

483

484

485

486

487

488

489

490

491

492

493

494

495

496

497

498

499

500

501

502

503

504

505

506

507

508

509

510

511

512

513

514

515

516

517

518

519

520

521

522

523

524

525

526

Iftner T, Haedicke-Jarboui J, Wu SY, and Chiang CM. 2017. Involvement of Brd4 in different steps of the papillomavirus life cycle. Virus Res 231:76-82. 10.1016/j.virusres.2016.12.006

Johnson DE, Burtness B, Leemans CR, Lui VWY, Bauman JE, and Grandis JR. 2020. Head and neck squamous cell carcinoma. Nat Rev Dis Primers 6:92. 10.1038/s41572-020-00224-3

Kim JS, Eom JI, Cheong JW, Choi AJ, Lee JK, Yang WI, and Min YH. 2007. Protein kinase CK2alpha as an unfavorable prognostic marker and novel therapeutic target in acute myeloid leukemia. Clinical cancer research : an official journal of the American Association for Cancer Research 13:10191028. 10.1158/1078-0432.CCR-06-1602

Klein JD, and Grandis JR. 2010. The molecular pathogenesis of head and neck cancer. Cancer biology \& therapy 9:1-7.

Laramas M, Pasquier D, Filhol O, Ringeisen F, Descotes JL, and Cochet C. 2007. Nuclear localization of protein kinase CK2 catalytic subunit (CK2alpha) is associated with poor prognostic factors in human prostate cancer. European Journal of Cancer 43:928-934. 10.1016/j.ejca.2006.11.021

Li ZS, Deng CZ, Ye YL, Yao K, Guo SJ, Chen JP, Li YH, Qin ZK, Liu ZW, Wang B, Zhao Q, Chen P, Mi QW, Chen XF, Han H, and Zhou FJ. 2017. More precise prediction in Chinese patients with penile squamous cell carcinoma: protein kinase CK2 $\alpha$ catalytic subunit (CK2 $\alpha$ ) as a poor prognosticator. Oncotarget 8:51542-51550. 10.18632/oncotarget.17935

Lin KY, Fang CL, Chen Y, Li CF, Chen SH, Kuo CY, Tai C, and Uen YH. 2010. Overexpression of nuclear protein kinase CK2 Beta subunit and prognosis in human gastric carcinoma. Annals of Surgical Oncology 17:1695-1702. 10.1245/s10434-010-0911-9

Lin KY, Tai C, Hsu JC, Li CF, Fang CL, Lai HC, Hseu YC, Lin YF, and Uen YH. 2011. Overexpression of Nuclear Protein Kinase CK2 alpha Catalytic Subunit (CK2alpha) as a Poor Prognosticator in Human Colorectal Cancer. PloS one 6:e17193. 10.1371/journal.pone.0017193

Nogueira MO, Hosek T, Calcada EO, Castiglia F, Massimi P, Banks L, Felli IC, and Pierattelli R. 2017. Monitoring HPV-16 E7 phosphorylation events. Virology 503:70-75. 10.1016/j.virol.2016.12.030

O-Charoenrat P, Rusch V, Talbot SG, Sarkaria I, Viale A, Socci N, Ngai I, Rao P, and Singh B. 2004. Casein kinase II alpha subunit and C1-inhibitor are independent predictors of outcome in patients with squamous cell carcinoma of the lung. Clin Cancer Res 10:5792-5803. 10.1158/1078-0432.CCR03-0317

Perea SE, Reyes O, Puchades Y, Mendoza O, Vispo NS, Torrens I, Santos A, Silva R, Acevedo B, Lopez E, Falcon V, and Alonso DF. 2004. Antitumor effect of a novel proapoptotic peptide that impairs the phosphorylation by the protein kinase 2 (casein kinase 2). Cancer Res 64:7127-7129. 64/19/7127 [pii]

10.1158/0008-5472.CAN-04-2086

Pfister DG, and Fury MG. 2014. New chapter in our understanding of human papillomavirus-related head and neck cancer. J Clin Oncol 32:3349-3352. 10.1200/JCO.2014.56.5754

Piirsoo A, Piirsoo M, Kala M, Sankovski E, Lototskaja E, Levin V, Salvi M, and Ustav M. 2019. Activity of CK2 $\alpha$ protein kinase is required for efficient replication of some HPV types. PLoS pathogens 15:e1007788. 10.1371/journal.ppat.1007788

Rampias T, Sasaki C, Weinberger P, and Psyrri A. 2009. E6 and e7 gene silencing and transformed phenotype of human papillomavirus 16-positive oropharyngeal cancer cells. J Nat/ Cancer Inst 101:412-423. 10.1093/jnci/djp017

Rosenthal DI, Harari PM, Giralt J, Bell D, Raben D, Liu J, Schulten J, Ang KK, and Bonner JA. 2016. Association of Human Papillomavirus and p16 Status With Outcomes in the IMCL-9815 Phase III Registration Trial for Patients With Locoregionally Advanced Oropharyngeal Squamous Cell Carcinoma of the Head and Neck Treated With Radiotherapy With or Without Cetuximab. J Clin Oncol 34:1300-1308. 10.1200/jco.2015.62.5970

PeerJ reviewing PDF | (2021:08:65093:2:0:NEW 22 Oct 2021) 
527

Ruzzene M, and Pinna LA. 2010. Addiction to protein kinase CK2: a common denominator of diverse cancer cells? Biochim Biophys Acta 1804:499-504. 10.1016/j.bbapap.2009.07.018

Sandulache VC, Hamblin J, Lai S, Pezzi T, Skinner HD, Khan NA, Dioun SM, Hartman C, Kramer J, Chiao E, Zhou X, and Zevallos JP. 2015. Oropharyngeal squamous cell carcinoma in the veteran population: Association with traditional carcinogen exposure and poor clinical outcomes. Head Neck 37:1246-1253. 10.1002/hed.23740

Sandulache VC, Lei YL, Heasley LE, Chang M, Amos Cl, Sturgis EM, Graboyes E, Chiao EY, Rogus-Pulia N, Lewis J, Madabhushi A, Frederick MJ, Sabichi A, Ittmann M, Yarbrough WG, Chung CH, Ferrarotto R, Mai W, Skinner HD, Duvvuri U, Gerngross P, and Sikora AG. 2020. Innovations in risk-stratification and treatment of Veterans with oropharynx cancer; roadmap of the 2019 Field Based Meeting. Oral Oncol 102:104440. 10.1016/j.oraloncology.2019.104440

Sarduy MR, Garcia I, Coca MA, Perera A, Torres LA, Valenzuela CM, Baladron I, Solares M, Reyes V, Hernandez I, Perera Y, Martinez YM, Molina L, Gonzalez YM, Ancizar JA, Prats A, Gonzalez L, Casaco CA, Acevedo BE, Lopez-Saura PA, Alonso DF, Gomez R, Perea-Rodriguez SE, and Group CIS. 2015. Optimizing CIGB-300 intralesional delivery in locally advanced cervical cancer. $\mathrm{Br} J$ Cancer 112:1636-1643. 10.1038/bjc.2015.137

Schwanhäusser B, Busse D, Li N, Dittmar G, Schuchhardt J, Wolf J, Chen W, and Selbach M. 2011. Global quantification of mammalian gene expression control. Nature 473:337-342. 10.1038/nature10098

Shay SG, Chang E, Lewis MS, and Wang MB. 2015. Characteristics of Human Papillomavirus-Associated Head and Neck Cancers in a Veteran Population. JAMA Otolaryngol Head Neck Surg 141:790796. 10.1001/jamaoto.2015.1447

Solares AM, Santana A, Baladron I, Valenzuela C, Gonzalez CA, Diaz A, Castillo D, Ramos T, Gomez R, Alonso DF, Herrera L, Sigman H, Perea SE, Acevedo BE, and Lopez-Saura P. 2009. Safety and preliminary efficacy data of a novel casein kinase 2 (CK2) peptide inhibitor administered intralesionally at four dose levels in patients with cervical malignancies. BMC Cancer 9:146. 10.1186/1471-2407-9-146

Trembley JH, Chen Z, Unger G, Slaton J, Kren BT, Van Waes C, and Ahmed K. 2010. Emergence of protein kinase CK2 as a key target in cancer therapy. BioFactors 36:187-195. 10.1002/biof.96

Trembley JH, Li B, Kren BT, Gravely AA, Caicedo-Granados E, Klein MA, and Ahmed K. 2021. CX-4945 and siRNA-Mediated Knockdown of CK2 Improves Cisplatin Response in HPV(+) and HPV(-) HNSCC Cell Lines. Biomedicines 9. 10.3390/biomedicines9050571

Trembley JH, Wang G, Unger G, Slaton J, and Ahmed K. 2009. CK2: a key player in cancer biology. Cell Mol Life Sci 66:1858-1867. 10.1007/s00018-009-9154-y

Zhou J, Zhao J, Sun K, Wang B, Wang L, Chen X, Zheng J, You Q, Wang X, Ding W, and Zhou J. 2014. Accurate and Economical Detection of ALK Positive Lung Adenocarcinoma with Semiquantitative Immunohistochemical Screening. PloS one 9:e92828. 10.1371/journal.pone.0092828

Zine El Abidine A, Tomaić V, Bel Haj Rhouma R, Massimi P, Guizani I, Boubaker S, Ennaifer E, and Banks L. 2017. A naturally occurring variant of HPV-16 E7 exerts increased transforming activity through acquisition of an additional phospho-acceptor site. Virology 500:218-225. 10.1016/j.virol.2016.10.023 


\section{Figure 1}

\section{Expression of CK2 $\alpha$ in OPSCC tumors}

(A) Representative field following CK2 $\alpha$ versus isotype control antibody IHC stain in OPSCC tumor tissue is shown. CK2 $\alpha$ was detected by DAB (brown). Blue depicts nuclei. Identity of staining antibody is indicated below each panel. Scale bar, $100 \mu \mathrm{m}$. (B) Representative fields of CK2 $\alpha$ IHC stain in OPSCC tumor tissues are shown with corresponding H\&E and Ki-67 stain in the same tumors. CK2 $\alpha$ and Ki-67 were detected by DAB (brown). Blue depicts nuclei. Identity of stain is indicated at the left and CK2 $\alpha$ score is indicated above the panels. $\mathrm{H} \& \mathrm{E}$, hematoxylin and eosin. Scale bar, $100 \mu \mathrm{m}$. 
A

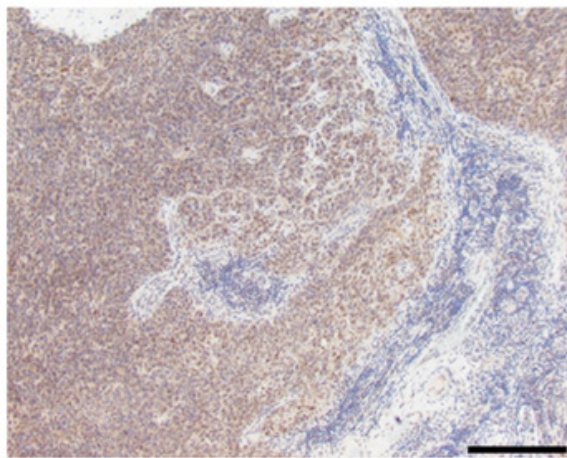

CK2 $\alpha$

B
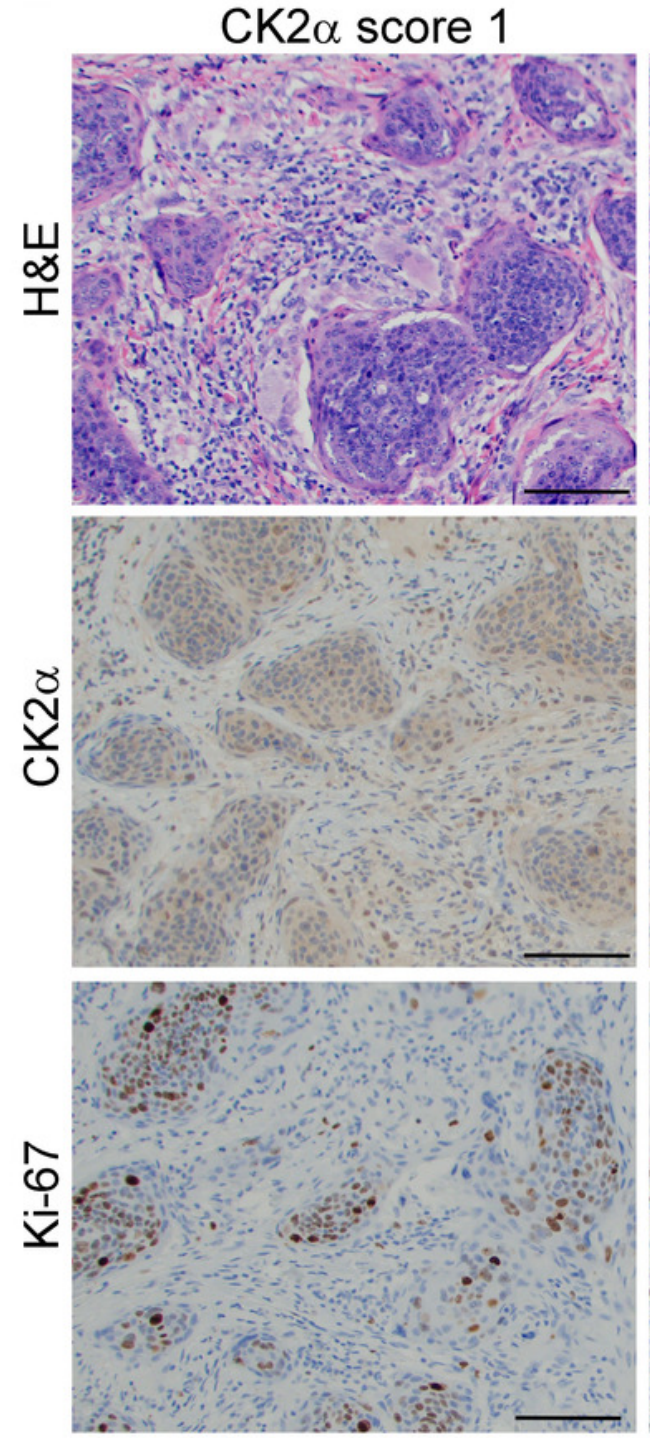

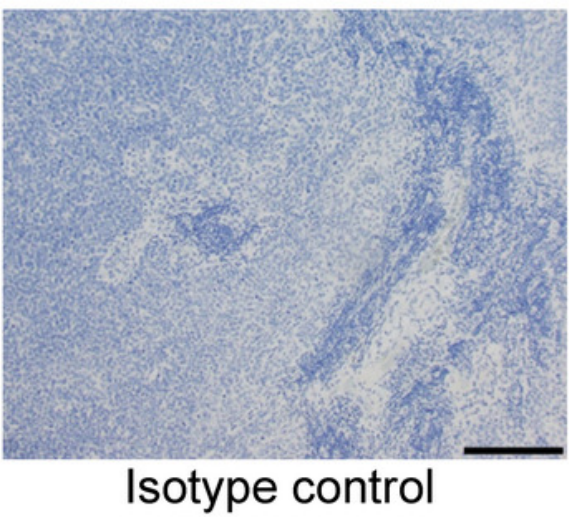

CK2 $\alpha$ score 2
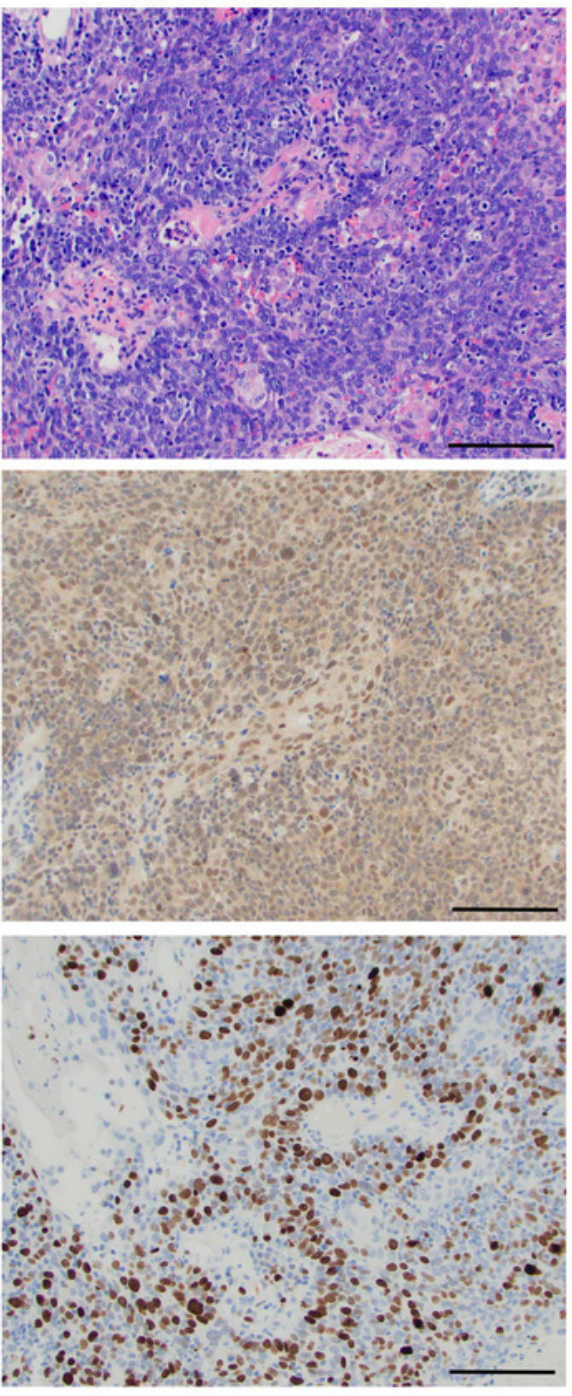
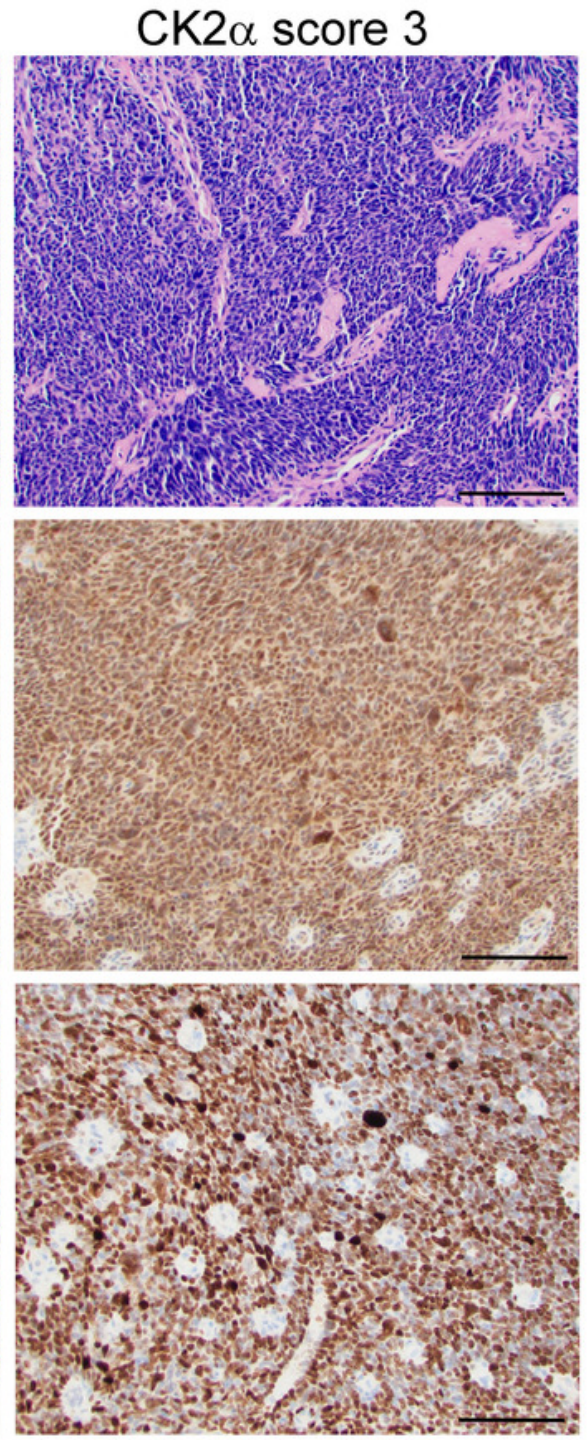
Figure 2

Survival curves based on CK2 $\alpha$ scores or HPV status in Minneapolis VA cohort.

Kaplan-Meier survival curves are shown. (A) OS according to CK2 $\alpha$ score. (B) OS according to HPV status. The legend identifying each survival curve line is indicated below each chart. 
A

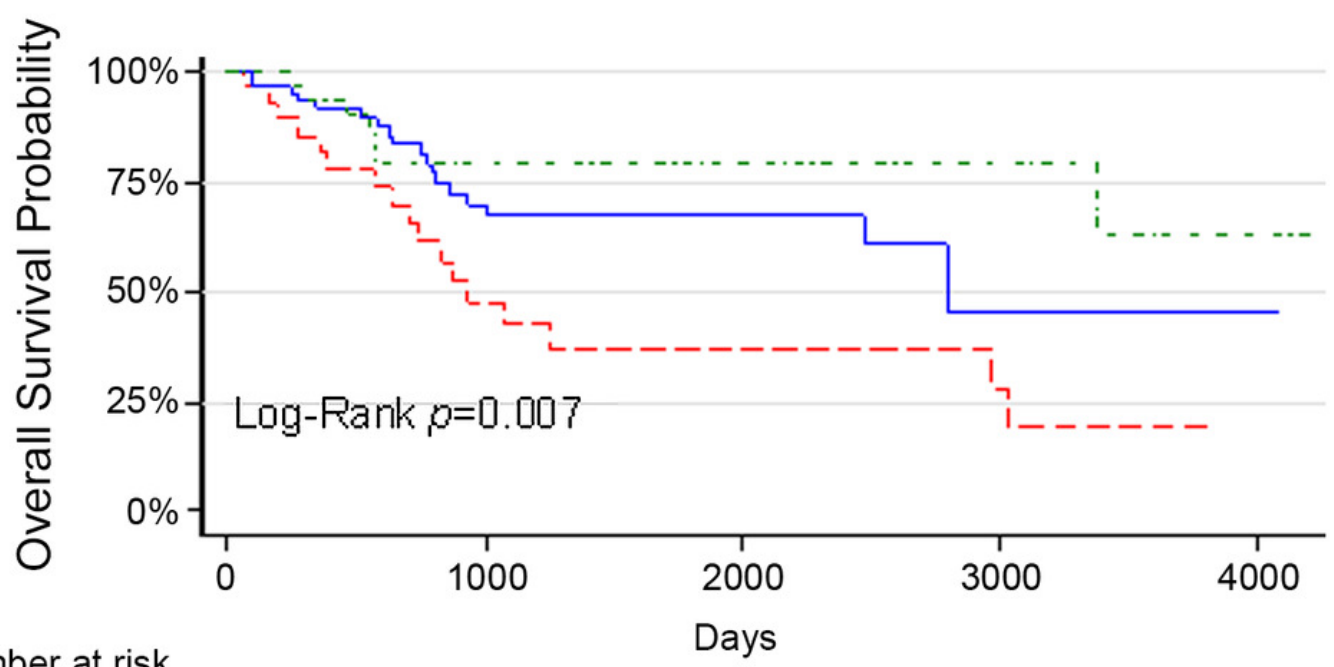

Number at risk

CK2 2128

$\mathrm{CK} 2 \alpha 2 \quad 60$

$\mathrm{CK} 2 \alpha 3 \quad 31$

10
28
17

5

14

11

$\begin{array}{ll}3 & 1 \\ 6 & 2\end{array}$

----- CK2 $\alpha$ score 1

CK2 $\alpha$ score 2

-....... CK2 $\alpha$ score 3

B

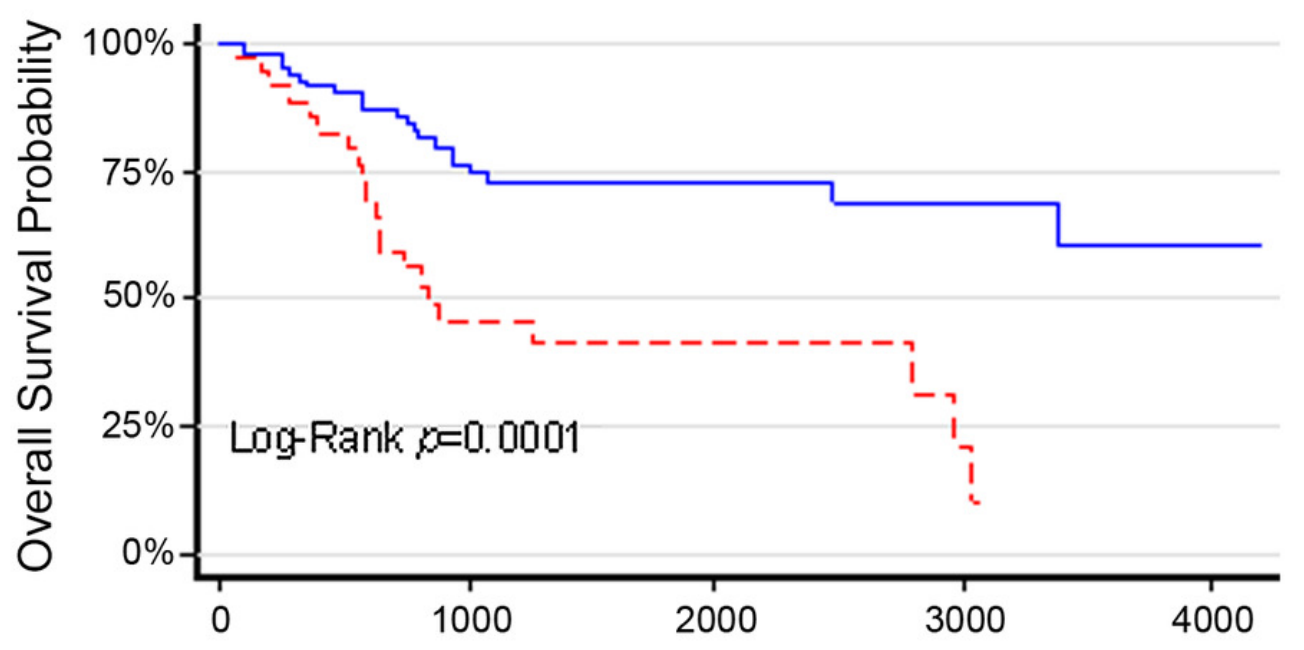

Number at risk

$\begin{array}{ll}H P V(-) & 35 \\ H P V(+) & 84\end{array}$

12

Days

$\mathrm{HPV}(+) 84$

43

6

24

10

0

$-----\operatorname{HPV}(-)$
$-\operatorname{HPV}(+)$ 
Figure 3

Disease-specific survival based on CSNK2A1 mRNA levels in HPV(-) HNSCC

Kaplan-Meier survival curve is shown for CSNK2A1 (CK2 $\alpha$ ) mRNA z-scores in HPV(-) HNSCC patients from TCGA RNA-seq data. The legend is indicated below the chart.

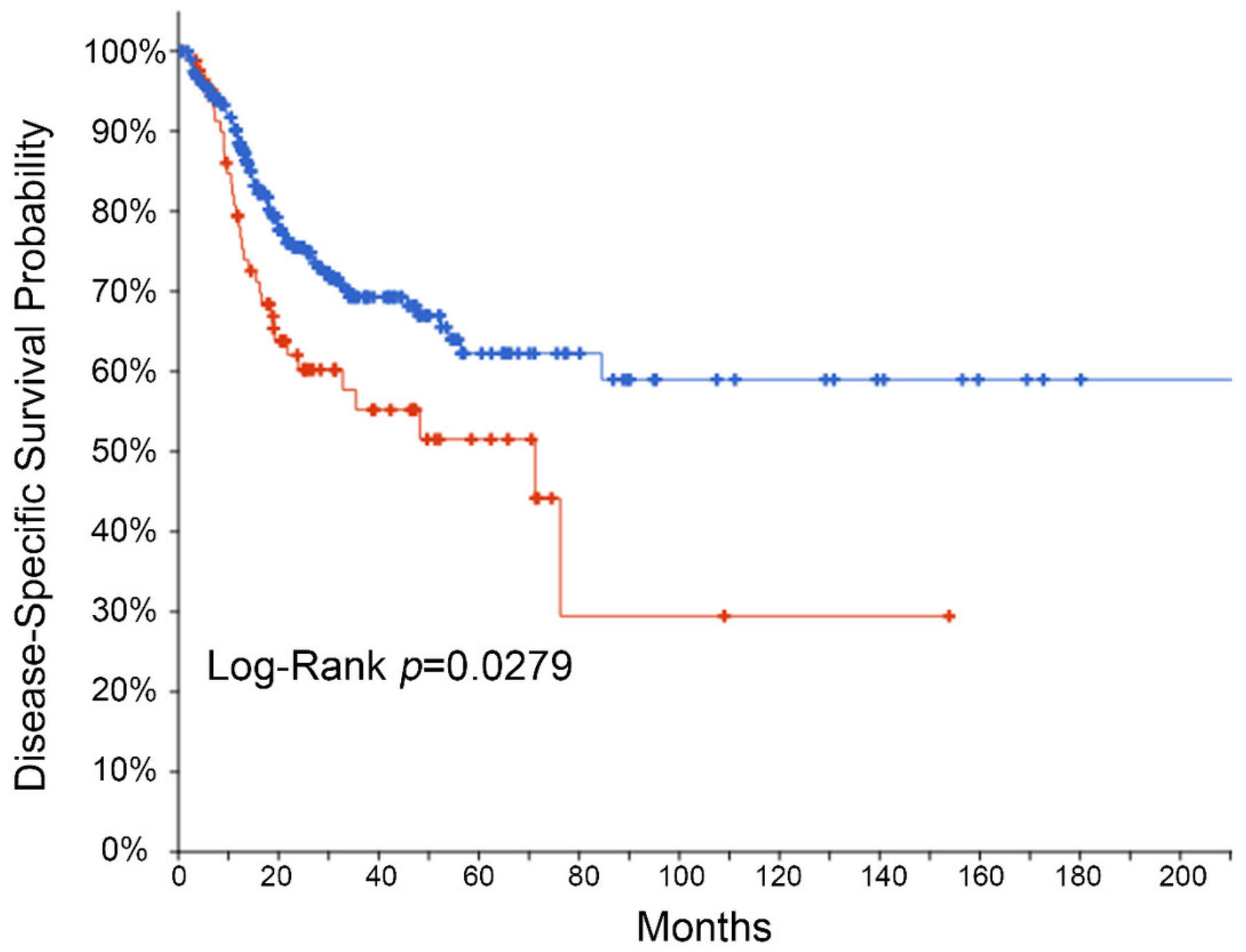

High CSNK2A1 RNA, $\mathrm{n}=117$

- Unaltered/low CSNK2A1 RNA, $\mathrm{n}=277$ 
Table $\mathbf{1}$ (on next page)

OPSCC Patient Characteristics 
Table 1. OPSCC Patient Characteristics

\begin{tabular}{|c|c|c|}
\hline & $\mathbf{n}$ & (Percentage) \\
\hline \multicolumn{3}{|l|}{ Gender } \\
\hline Male & 119 & $(100)$ \\
\hline Age & $63 \pm 7.2$ & $(100)$ \\
\hline \multicolumn{3}{|l|}{ Smoking status } \\
\hline Current & 58 & $(48.7)$ \\
\hline Former & 54 & $(45.4)$ \\
\hline Never & 7 & $(5.9)^{\prime}$ \\
\hline \multicolumn{3}{|l|}{ Alcohol Use } \\
\hline Current & 58 & $(48.7)$ \\
\hline Former & 42 & (35.3) \\
\hline Non-drinker & 19 & (16.0) \\
\hline \multicolumn{3}{|l|}{ Tumor Site } \\
\hline Tonsil & 68 & $(58.6)$ \\
\hline Base of Tongue & 41 & (35.3) \\
\hline Soft Palate & 6 & $(5.2)$ \\
\hline Pharyngeal Wall & 1 & $(0.9)$ \\
\hline \multicolumn{3}{|l|}{ T Classification } \\
\hline T1 & 46 & (38.7) \\
\hline $\mathrm{T} 2$ & 39 & (32.8) \\
\hline T3 & 19 & $(16.0)$ \\
\hline $\mathrm{T} 4$ & 15 & (12.6) \\
\hline \multicolumn{3}{|l|}{ N Classification } \\
\hline No & 24 & $(20.2)$ \\
\hline N1 & 14 & (11.8) \\
\hline N2 & 72 & $(60.5)$ \\
\hline N3 & 9 & $(7.5)^{\prime}$ \\
\hline \multicolumn{3}{|l|}{ TNM Stage (AJCC) } \\
\hline l & 10 & $(8.4)$ \\
\hline II & 9 & (7.6) \\
\hline III & 16 & (13.4) \\
\hline IVA & 73 & (61.3) \\
\hline IVB & 11 & $(9.2)$ \\
\hline \multicolumn{3}{|l|}{ Initial Treatment } \\
\hline Surgery & 12 & (10.1) \\
\hline Radiation & 12 & (10.1) \\
\hline CCRT & 69 & $(58.0)$ \\
\hline Surgery/Radiation & 6 & $(5.0)$ \\
\hline Surgery/CCRT & 20 & (16.8) \\
\hline
\end{tabular}

1 
Table 2 (on next page)

OPSCC tumor data according to CK2 $\alpha$ score 
Table 2. OPSCC tumor data according to $C K 2 \alpha$ score

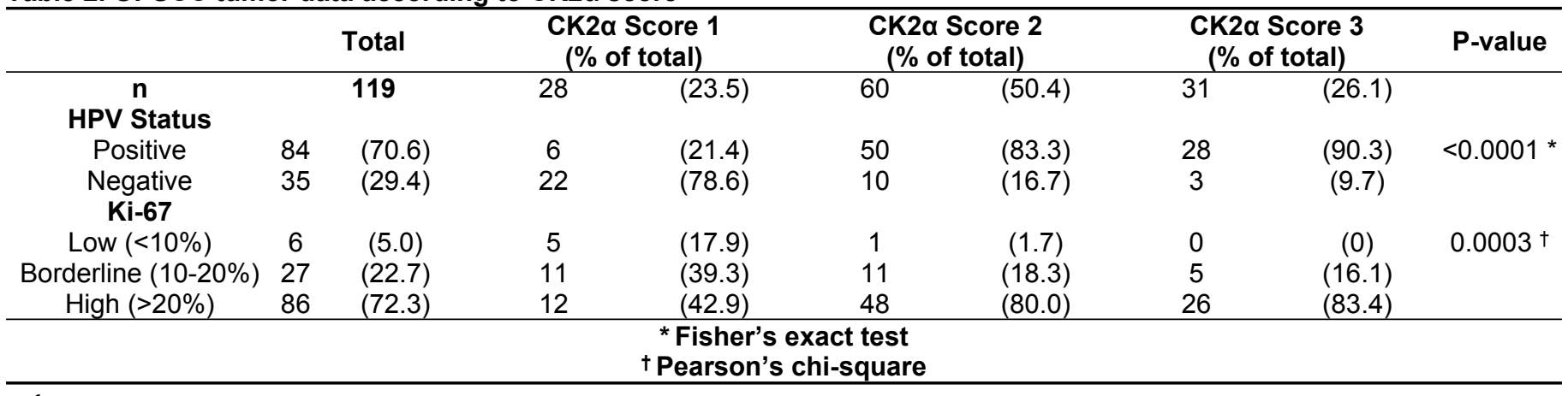

1 
Table 3 (on next page)

Cox univariate regression analysis for overall survival 
Table 3. Cox univariate regression analysis for overall survival

\begin{tabular}{llcc}
\hline Variable & & HR (95\% Cl) & $\boldsymbol{P ~ V a l u e ~}$ \\
\hline CK2a & High (score 2 \& 3) vs. low (score 1) & $0.398(0.214,0.738)$ & 0.0035 \\
HPV & Negative vs. Positive & $3.128(1.692,5.783)$ & 0.0003 \\
Ki-67 & Low $(\leq 20 \%)$ vs. high $(>20 \%)$ & $1.587(0.834,3.020)$ & 0.1596 \\
Age & Per year increase & $1.011(0.970,1.053)$ & 0.6095 \\
Alcohol & current/former vs. non-drinker & $1.655(0.590,4.641)$ & 0.3380 \\
Smoking & Current vs. former/never & $2.359(1.232,4.517)$ & 0.0096 \\
T Classification & T3-4 vs. T1-2 & $1.304(0.685,2.481)$ & 0.4192 \\
N Classification & N1, N2, \& N3 vs. N0 & $1.259(0.580,2.730)$ & 0.5601 \\
TNM Stage (AJCC) & Per increase in stage & $1.152(0.852,1.558)$ & 0.3582 \\
Treatment & CCRT vs. Surgery & $1.300(0.451,3.747)$ & 0.6269 \\
& Surgery/CCRT vs. Surgery & $0.584(0.162,2.109)$ & 0.4116 \\
& Surgery/Radiation vs. Surgery & $0.438(0.049,3.950)$ & 0.4619 \\
& Radiation vs. Surgery & $1.407(0.376,5.270)$ & 0.6122 \\
\hline
\end{tabular}

CCRT, concurrent chemoradiation 